\title{
Technoculture: Subjectivity in the Net of Music
}

\begin{abstract}
VESNA MIKIĆ
Thinking technoculture in terms of reality production inevitably results in a transformed experience of space, followed by equally transformed notions of the subject and reality as such. In this respect, metaphors of cyberspace, virtual reality, cyborgs, etc. are some of the most vivid points of technoculture.[1] Thinking about them is almost impossible, however, without understanding, if not constantly pointing out, the necessity of the existing technological support for entering these alternative spaces and creating these artificial worlds, for the "existence" of these "scary" (Haraway, 1991: 26) inhabitants of cyberspace, in other words, without the very moment in which all this becomes possible: without logging into some kind of net and without networking. That is why the concept of the net is conceived here mostly in respect to the interactiveness upon which technocultural networking relies, and networking is conceived of as an action through which one can obtain various ever different, constantly changeable experiences of space, which in turn can be understood as experiences of dwelling in the net. It turns out that the notion of net in some way conditions every further discussion of technoculture phenomena, and since the various everyday actions could be, eventually, considered as various types of networking, I approach it here as one more distinctive technocultural metaphor.

Studying music in technoculture, or more precisely, music in relation to some of the above-mentioned technocultural metaphors, led me to the conclusion that music also exhibits all the essential features of technoculture. Most probably thanks to its interactive aspect, it is possible to talk not only about music in technoculture, which is produced, reproduced and consumed by the means of digital technology and to which I apply the term technomusic derived from the notion of technoculture, but about music in general.
\end{abstract}


It is possible, then, to think of the things that could be understood as networking in music, with or without technology. If we would like to learn more about subjectivity in the context of music created in technoculture, inevitably we are faced with questions linked to the status of the subject in technoculture in general, and these are questions concerning the creation of reality, the place of the subject in it, questions concerning the subject's body... What in music is close to the notions of virtual reality and alternative worlds, what can be understood as a subject and what as a body?

Since all these notions are very strongly connected to each other, almost emerging one from the other, I will first examine the possibility of transposing the elements needed to establish the notion of alternative spaces, or "dwelling in the network," to music creation and perception in general, from the point of view of the unavoidable elements needed for establishing the sonorous net in which music primarily exists (here I will not deal with the possible net of musical meanings).

MUSIC AND THE MEANS OF PRODUCING ALTERNATIVE

WORLDS, THE MEANS OF “DWELLING IN THE NET”

The technocultural production of reality is based on the creation of various artificial worlds by means of technological devices. In this respect one of the most appealing technologies in technoculture is VR technology. However, as Heim (1998: 4) points out, one should be careful with the use of the term as there is the difference between VR in the broader sense and VR in the narrower sense, which is applied to VR technology itself. This technology is based on, as Heim calls them, three I's that stand for: immersion, interaction and information intensity, while VR in the broader sense is usually applied to various aspects of life and activities based upon the idea of constructing some kind of virtual world. Thinking music from this point of view leads to the conclusion that music could easily be understood as VR in the broader sense, while of all the arts it is the closest to VR in the narrower sense, bearing in mind the requirements of the three I's. The fact is that music relies on interaction (for example, the relations of composer-work, composer-performer, performer-performer, performers-audience, etc.) and as such, on a more or less intensive flow of music information, while immersion is realized in its structural aspect, as well as the "reality" of its worlds constructed 
on sequences of specific music events (Mikić, 2003: 29). When technology is called upon, all the potential of music is enhanced by the possibilities for an ever more intensive information flow (with respect also to velocity and variety), as well as better, more faithful immersion. Interaction is now expanded to the domain of non-traditional instruments, which surely enables the creation of total and unpredictable artificial music worlds, which approach the demands of VR technology in relating to the "primary" music world and the "primary" world we live in, without trying to imitate them (Heim, 1998: 98).

Naturally, the technocultural subject is very different from the traditional one. Because it exists in a decentralized world, its notions of what is near and what far away, of community and neighborhood (Negroponte, 1995: 7) are forever changed, and its everyday life strongly relates to technology and the ecstasy of communication. Instead of the rational human subject, who is the center of its own world, we find a miniaturized, partialized subject, one equated with an object (Baudrillard, 1994: 26), multiplied, living in the system of heterarchy (Menser, 1996: 294), and transformed into an "inapproriate/d other" (Haraway, 1991: 26). The idea of living in the ecstasy of communication, which led Baudrillard to his "desire for an object," also brings into play the concept of interobjectivity, where "[ $t]$ he observer does not have the position of a subject related to an object but becomes an object itself within interobjectivity. Interobjectivity is the case or theory of the elimination of the 'anthropological predicate' (as Gilles Deleuze calls it)" (Bora, 1997: 2).

\section{( TECHNO)SUBJECT-IVITY IN MUSIC}

The subject in traditional music reflects the rationalistic notion of the subject. This is evident already at the level of language (music themes called in various languages: subject, sujet, soggetto...). However, that kind of subjectivity is rarely to be found in music nowadays. Rather, it exposes some features characteristic of the contemporary subject's destiny. Thus, in the case of electroacoustic/technomusic it is possible to speak of the subject/body metaphor at the level of music/sound material, medium, sound object, music piece... Some of these features can be seen in the piece Vris.Krik.exe (2000) by the Serbian composer Jasna 
Veličković (Belgrade, 1973), the first Concerto for live electronic orchestra in the history of Serbian music.

Let's begin with the title, which is very relevant for our topic, and try to clarify the net of relations - the relations of meanings that it conveys, as well as the music relations that it hints at. In Serbian, the title is a combination of two synonyms - vrisak and krik, which mean yell and scream, respectively - and the first word has been shortened (vris instead of vrisak). The composer explains that the interaction of strokes and suffocation bring about the scream, the yell, and continues: "VrisKrik.EXE means at the same time leaving, ending - disappearance of the yell (scream). The Latin verb exeo, exire means to walk out, to leave, to end, to pass, to disappear, to flow out. We can also find the root of this verb in the English word exit, and the form exe has also meaning of the computer command important for the creation of this piece" (Veličković, 2000: preface to the score). Ambiguity already indicates the double or multiple play of the postmodern subject or object logged onto the net, but the last word (or abbreviation), exe, seems to be the key one. Exe as a command, as an imperative, as the denotation of an computer execution file, is further clarified by the composer quoting the dialogue of Humpty Dumpty and Alice in Lewis Carroll's Through the looking glass and what Alice found there:[2]

'When I use a word,' said Humpty Dumpty with contempt, 'it has the exact meaning that I choose, no more no less.'

'The question is,' said Alice, 'whether you can make words have so many different meanings.'

'The question is,' said Humpty Dumpty, 'who is the master - that's all.'

As Miško Šuvaković has written: "Every rationality must be confronted with its very roots in nonsense. Every certainty must be confronted with the horror of yelling and screaming. Every act must, in the end, be an executive (exe) act" (Šuvaković, 2001: 339-48). So the moment of command execution, the moment of establishing domination, is one of the questions this piece gives rise to. Also, there is the question of sense, more precisely, of nonsense, which is established by the subject's equalizing itself with objective reality, by the subject's facing its image of an "inappropriate/d other" not in the mirror, but on the flat screen surface, with the face it sees there transformed by a scream. The organization of the piece resembles a mirror. It falls into sections called 
Nowhere, Zoom In I, Humpty Dumpty, Zoom In II and Now Here. The image of the real, i.e. "the conflict of the lonely, powerless, lost but conscious being with the synthetic, mechanized, inert, multiplied reality" (Veličković, 2000: preface to the score) is created in the first two sections, while, after a collision with the screen flatness in the Humpty Dumpty section, the section disposition is reversed, depicting going back to the "real," here and now, which is not (judging by the material used) much different; but it is enriched by the horror of experienced zoom-ins.

Thus, the whole net of the piece is woven around a traditional battle for domination, making sense out of nonsense, a simulation of the subject's shaping, and this can be traced in all the work's interactive aspects. The very acceptance of the way things are at the end of the piece leads one to think of the equalization of subject and object, and the interobjective nature of interaction.

With respect to the role that various participants in the work play, from the point of view of the music matter used, the equalization is obvious. This is not a classical concert. Heterarchy, the system of individuals who freely change places, is called upon. But the heterarchy of the piece (which doesn't exclude hierarchy) is controlled by a master of ceremonies, the author/user who, commanding and playing the electronic instruments, "calls" various samples from the sound bank. Heterarchy is achieved by the somewhat endless multiplication of motives in realizing the picture of "multiplied, inert reality." The attempt to trace the subject as a sound material is also possible in the domain of the piece's previously prepared sound elements, stored in the sound bank and performed with live electronics. Here the composer uses sounds that are in direct relation to the human subject (human voice, heavy breathing, hammer stroke...) and processes them by computer. These samples can be heard at the very beginning of Zoom in I, combined with severe strokes, which will afterwards provoke the first culmination based upon horizontal/repetitive and vertical multiplication of music materials/subjects/objects (examples 1 and 2). It can also be found at the beginning of the central section, the only one which really contrasts with the rest of the piece, in which these sounds can be interpreted as a transformed, partialized, and hybrid subject, the subject as an "inappropriate/d other," a dweller in the work's net, who is, at the end, the image of ourselves. 
Also, with respect to the subject/sound-music material as well as with respect to the subject/medium, the same conclusion can be drawn: the composer equalizes subject and object - she freely manipulates materials and instruments trying to realize a specific music net, an instant reality, which in itself has the potential of a different disposition of forces, but which is fixed by the score.

\section{( TECHNO)BODY IN MUSIC}

Suffocation and strokes, mentioned a few times, truly link us with bodily sensations. This is one of the reasons why, in the case of our piece, it is possible to speak of the metaphor of a body in the net of a piece of music. Not only does that physical/bodily suffering lead to a scream, but the scream itself transforms the face/body, while the zooming in of the mirror prolongs, stretches the body or its parts. The transfigured body, the body with prosthesis, the hybrid body are all technocultural bodies that we adopt in our various daily life networkings (technological, leisure time, sexual). Musically considered, the metaphor of the body can be located in the treatment of the medium or structural procedures. I have already mentioned that the piece leads towards the transformation of subject into object. The live electronic instruments are treated in the same way as traditional instruments are. There are no attempts to imitate traditional instruments that could lead to some hybrid types. There is no intention of overwhelming the orchestra, which could lead to the bodily transformation of the traditional instruments. The key word here is interaction, the mutual influence of the participants on each other and their saturation, their relations. We do, however, as one of the final results of this interaction, get the hybrid body of the concert itself.

As far as structure is concerned, we could speak in terms of one of the most appealing segments of technocultural discourse: of a net virus, a body virus, a virus in a piece of music. In the context of the body/net of the piece, the section entitled Humpty Dumpty acts as a kind of virus (realized in live electronics and orchestra; its slow pace and very transparent texture are quite different from the rest of the piece), but it "helps" to structure the rest of the work. The point of this section is to induce a change in point of view, after which the subject/object's body learns to live with the virus, to be an "inappropriate/d other." Maybe 
there lies the explanation for the word game in the last section in comparison to the first one: Now here instead of Nowhere (example 3).

If it is possible to observe some of the above-mentioned basic features of subjectivity in technoculture in Vris.krik.exe, then, and bearing in mind that a network in which the various technocultural aspects reveal themselves is necessary, the metaphorical interpretation of the multiplication, transformation and objectivization of technocultural subjectivity in the context of the piece of music under consideration here, in terms of a specific music network realized by the interaction of electronic and traditional media, becomes possible. The engagement of the author-performer, the performers and the audience in the processes by which the piece is created, performed and consumed give rise to some important issues concerning "dwelling" in the network. These are:

1) logging in - for the composer, the process of sampling, the act of composing and performing, the process of preparing and the performance itself for the performers, and listening to the performance for the audience and all the other participants;

2) interaction - the exchange of the music content between the performers and in the performers-audience relation and vice versa (repetition of motifs, their minor transformations, transformed "memories" of some of them in the last section of the piece; on the symbolic level the exchange of strokes, shifts of suffocations and strokes). Along with interaction goes communication (the intensive flow of information - the multiplication of musical motifs). In this respect, dwelling in the net of the piece could be interpreted as an interobjective situation, while in the context of the question of power there could be some kind of intersubjective relation;

3) immersion - thanks to the sense of the totality of the world of the piece (realized through its spiral structure, a symmetry which does not imply exact repetition of the past events, but repetition which could be understood as a new circle of the spiral), as well as its unpredictability (at the structural level created in the Humpty Dumpty section metaphorically, the net or biological virus's unpredictability), but also through its relationship to primary musical and "real" worlds (samples of non-musical sounds), which are the conditions for the successful realization of some virtual world.[3]

4) Finally, in the very moment of logging out of the network, there is a question of our experience of the world changing. There's no return. In the moment when the piece is over, the experience of all those who have 
participated in its realization changes. It is as if the notion of irreversible change, which happens after networking, stimulated by the way the piece is created, and in the context of technocultural subjectivity confronted with absurdity and trying to create some kind of sense, even momentarily, carries within it the germ of one more possible positioning of the (human) subject in technoculture.

Dealing with a somewhat different issue, the religious aspects of technoculture, Erik Davies risks being accused of romanticism in his discussion of technologies of deepening awareness and attention (which are idiosyncratic for spiritual practices) based on engaging the imagination in order to produce more imaginative ways for dwelling in the Net, since there is no way to ignore or avoid it:

Attention is the evanescent point of capture and resistance. The more awareness you have about the way your attention works on a moment-to-moment level, the more suppleness, the more space will form around that activity. Your tactics change. You notice absences. It's not that you are no longer captured, seduced or compelled, or that you escape somehow to some realm where you can completely control your experience of the world. But psychodynamic and contemplative practices which deepen awareness and attention give you a sort of edge, a more fluid and tactical intelligence. To speak mythically, this is not gnostic escape - it is a gnosis that punctures the simulacra of the archons, and which discovers - not the true representations that organize existence - but rather the non-commodifiable networks that transcend representation and link us hopelessly to this real world, to this unavoidable here and now. (Davies, 1997: 7)

It is as if Jasna Veličković is saying: Yes, here and now, but of the conscious subject, and with the potential as well to imagine (to exit into) the disposition of the elements in the (even instant) network of its existence.

\section{EN D NOTES}

[1] The closeness of technoculture and ideology as a reality production could be brought up by accepting Menser/Aronowitz's "complexity theory" (as opposed to deterministic ones) and trying to observe the different relations in which cultures, technologies and sciences coexist and from the viewpoint of cultural studies as studies that "always emerges 'in the middle of things', within a certain set of surroundings-historical, temporal, geographic, ethnic, sexual, technological- that is, in a milieu..." Michael Menser and Stanley Aronowitz, “On Cultural Studies, Science and Technology,' 
Technoscience and Cyberculture, Eds. Stanley Aronowitz, Barbara Martinsons and Michael Menser, Routledge, New York, 1996, 7.

[2] This quotation is the only reference to the book, and Humpty Dumpty, or more precisely - the encounter of Alice and Humtpy Dumpty, is realized in the section of the piece entitled Humpty Dumpty, which will be discussed below. In the context of this paper Humpty Dumpty should be perceived as a 'cyborg,' or an 'inappropriate/d other' in the net/space of the piece, the very one who changes our experience of ourselves, who teaches us to be 'inapproprate/d others,' too.

[3] On possible parallels between music and VR in boarder sense, and music and VR technology I wrote in more details in: Music and/or virtual reality?, New Sound, 21, 2003, 29-35. The basic idea is that the music through interaction and its temporal quality gains some kind of spatiality. Further more, considering the fact that music has its own primary world, as well as it could sometimes relate to 'real' primary world makes it perfect kind of virtual reality, which due to music's nature becomes very close to the VR technology.

REFERENCES

Baudrillard, Jean. Drugo od istog (Le même de l'autre). Beograd: Lapis, 1994.

Bora, Gabor. "Interobjectivity: The Link from Communication to Information and Back Again." http:/ / www.nettime.org 1997.

Davies, Erik. "Technoculture and the Religious Imagination." http:/ / www.nettime.org 1997.

Haim, Michael. Virtual Realism. Oxford, New York: Oxford University Press, 1998.

Haraway, Donna. "The Actors are Cyborgs, Nature is Coyote and the Geography is Elsewhere: Postscript to 'Cyborgs at Large.'” In: Technoculture, eds. Constance Penley and Andrew Ross. Minneapolis, Oxford: University of Minnesota Press, 1991: 21-7.

Menser, Michael. "Becoming Heterarch - On Technocultural Theory, Minor Science and the Production of Space." In: Technoscience and Cyberculture, eds. Stanley Aronowitz, Barbara Martinsons and Michael Menser with Jennifer Rich. New York and London: Routledge 1996: 293-317.

Mikić, Vesna. “Music and/or Virtual Reality?" New Sound: International Magazine for Music (2003): 29-35.

Šuvaković, Miško. Paragrami tela/figure. Beograd: CENPI, 2001. 
Veličković, Jasna. Vris.Krik.exe, perface to score, Beograd, 2000.

University of Arts, Faculty of Music

Dept. of Musicology and Ethnomusicology

Kralja Milana 50, 11000 Beograd, Serbia

mikic@eunet.yu; mikic@fmu.bg.ac.yu 